\title{
Fishery Aspect of Horseshoe Crab [Tachypleus gigas (Müller, 1785)] in the Peninsular Malaysia: Exploitation Status
}

\author{
Mohd Razali, M. R., Zaleha, K. \\ Kulliyyah of Science, International Islamic University Malaysia, Malaysia
}

Copyright $(2017$ by authors, all rights reserved. Authors agree that this article remains permanently open access under the terms of the Creative Commons Attribution License 4.0 International License

\begin{abstract}
Horseshoe crab is a unique Arthropoda which is also known as a living fossil because of its ancient morphological appearance. The animal established its existence since 300 million years ago and maintained its morphology to present day. The greatest proportion of adult horseshoe crab mortality is probably due to human activity. Horseshoe crabs in Malaysia are harvested for local consumption or marketed to the neighbor country. Series of survey were carried out to understand the exploitation status and collection technique of horseshoe crab in selected coast, Pahang and Malacca coastal area. Interviews were carried out with fisherman that involved in horseshoe crab exploitation activities. Data collected from 100 respondents were analyzed to compare the exploitation activity in both coastal areas. Respondents were mostly fisherman which used both techniques; collecting on shoreline and net fishing to catch horseshoe crab. More people significantly $(\mathrm{p}<0.05)$ used traditional collection method (hand harvest at shoreline) in Pahang (56.1\%) compared to those in Malacca (34.15\%). $65.85 \%$ collectors in Malacca adopted the netting method while, only $43.9 \%$ collectors in Pahang preferred the same method to collect adult horseshoe crabs coming to the shore during spawning season. The frequency of netting method monthly was significantly higher $(\mathrm{p}<0.05)$ in Malacca than Pahang. This resulted to the higher horseshoe crab quantities caught by 50 respondents in Malacca (16860 per month) than Pahang (4180 per month). The initial results from this survey indicate an alarming condition faced by the horseshoe crab coming to the beach for nesting. Monitoring program should be planned to sustain the fishery activity on horseshoe crab in Malaysia.
\end{abstract}

Keywords Tachypleus gigas, Horseshoe Crab, Exploitation Status, Catching Method, Conservation

\section{Introduction}

Horseshoe crab is a unique arthropod that existed since 300 million years ago and known as a living fossil according to its ancient morphological appearance. The animal established its existence and maintained its descendent features from the Late Ordovician Period to present day [1]. However, only 4 species are still existed nowadays and distribute sympatrically around the world [2]. Tachypleus gigas (Müller, 1785) commonly found in Asia coastal water [3] from India to Japan and south to Indonesia [4][5][6] and Malaysia [7]. The Asian horseshoe crab, T. gigas live in sandy to muddy habitats [8][9][10]. A few decades ago, millions of horseshoe crabs were harvested annually and were commercially used as bait in fishery activity, fertilizer in agricultural activity and livestock's feed due to low commercial value [11].

Horseshoe crabs in Malaysia are mainly used as food for local consumption or marketed to the neighbor country [12][13]. Previous study encountered that clotting agent in horseshoe cabs blue copper-based blood; amoebocyte lysate could be used to test the purity of medicines and the sterility of apparatus in pharmaceutical analysis [14][15]. Amoebocyte lysate clots when exposed to endotoxin that released by infectious bacteria. $T$. gigas has been identified as a species that could be used to produce the Tachypleus amoebocyte lysate (TAL) in substituting the utilization of Limulus polyphemus in the production of Limulus amoebocyte lysate (LAL) [16]. The number of the Atlantic Horseshoe Crab, L. Polyphemus that solely utilized in the production of horseshoe crabs blood is dwindling [17].

These factors could increase the Asian horseshoe crabs' commercial value in future. However, surge in market value may serve as an intrinsic exploitation-depend mechanism that possibly lead to the overexploitation. Overexploitation is known as an anthropogenic pressure [18] that may causes loss of the crab's population as a consequent of entrapment 
in fishing nets in coastal waters [19] or collected at shoreline during spawning season.

In addition to loss of population, horseshoe crabs were threatened by harvesting activity at the spawning site that may inhibit the breeding success. Adult horseshoe crabs are loyal to their local spawning site [20][21]. Since the greatest proportion of adult horseshoe crabs' mortality is probably due to human activity [18][22], the exploitation should be monitored to ensure the sustainability of this species. However, most of the available information on horseshoe crab exploitation was derived from the Atlantic species. As noted by [23], the extensive study on $T$. gigas exploitation status in Malaysian coast is urgently needed for future conservation. The present study aimed to report the exploitation status of the horseshoe crab in selected coasts at Pahang and Malacca which currently become important spots for harvesting $T$. gigas.

\section{Materials and Methods}

Series of interviews were conducted at fisherman's jetties along Pahang and Malacca area that involved in horseshoe crab harvesting activity (Figure 1). Those respondents (fishermen) were informed on the purpose of the research and verbal consent was obtained. This methodology was chosen to avoid bias because some respondents would not have writing and reading skill. Respondent's name and interview date were written on the questionnaire sheet once the respondent agreed to be interviewed. Respondent were informed that all information provided would be anonymized. Interviews were conducted with 50 fishermen at Pahang and Malacca respectively from November 2015 to February 2016.

There are two types of method that commonly used by the local fisherman to harvest horseshoe crab; hand harvest the landing horseshoe crabs at shoreline and entangle the horseshoe crabs at the open sea by the netting gear. Hand harvest at shoreline could be classified as a traditional method as this method has lower fishing effort than netting method. Netting method could be classified as a modern method since the application of the fishing gear is closely related with the latest innovation that would increases the fishing effort. Respondent were approached by the snowball sampling, where the peers would indicate the next respondent that actively involved in horseshoe crab collecting activity. Respondent were interviewed separately to avoid the answer interfering by the pals.

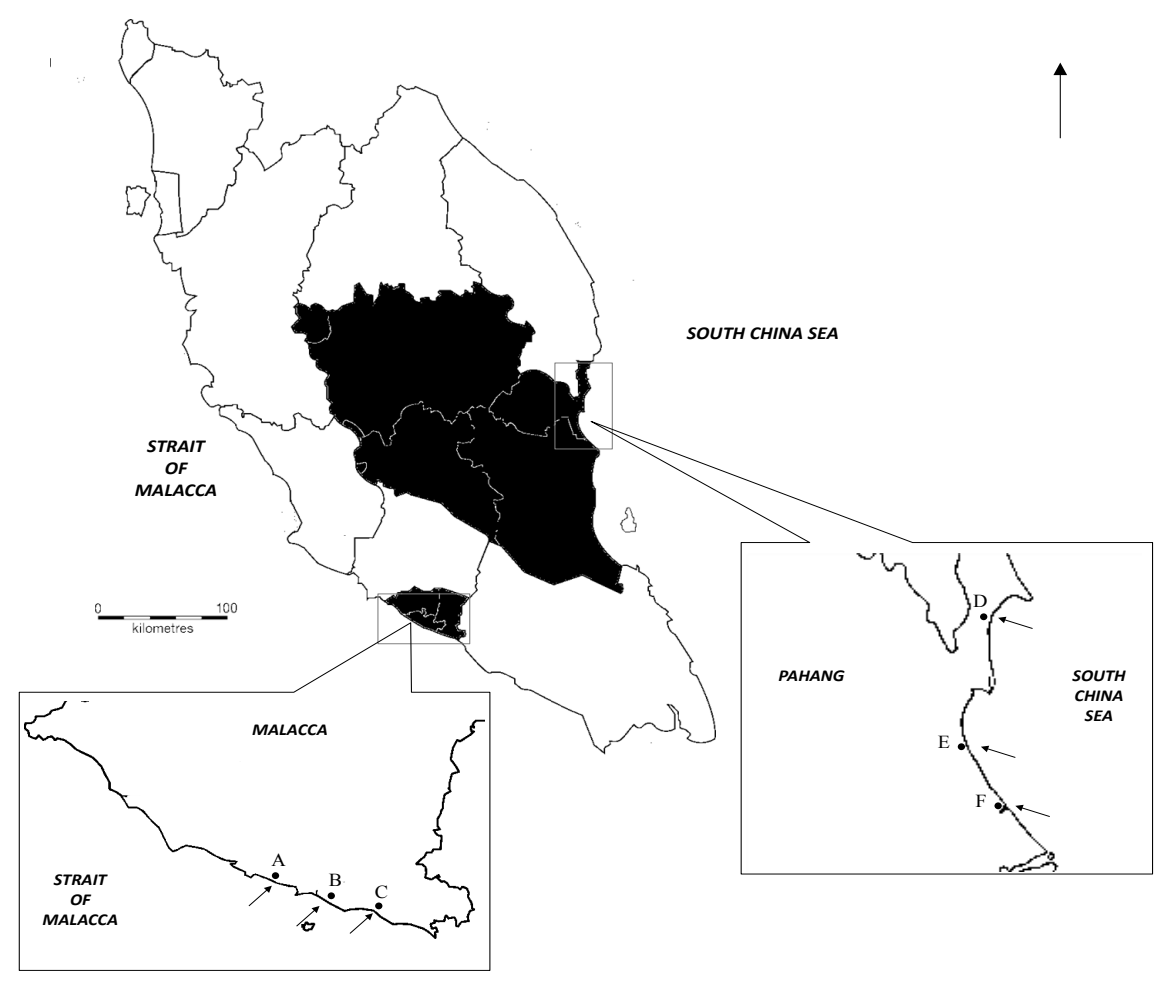

Figure 1. Locations of the conducted survey at Malacca and Pahang coastal areas. A: Sungai Duyung (N 02 ${ }^{\circ} 10^{\prime} 28.0^{\prime \prime}$ E $\left.102^{\circ} 17^{\prime} 22.2^{\prime \prime}\right)$; B: Anjung Batu (N

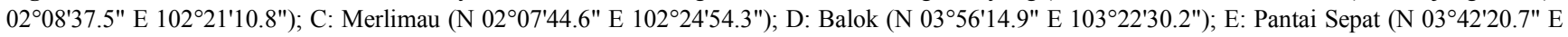
$\left.103^{\circ} 20^{\prime} 07.1^{\prime \prime}\right) ;$ F: Cherok Paloh (N 033' $17.1^{\prime \prime}$ E $\left.103^{\circ} 22^{\prime} 51.0^{\prime \prime}\right)$ 
Respondents were asked with a few questions; What is the most preference method that commonly used (hand harvest the landing horseshoe crabs at shoreline or entangle the horseshoe crabs at the open sea by the netting gear) to harvest the horseshoe crab? How frequent you apply the preference method to harvest horseshoe crabs per month? and How many horseshoe crab could be collected for every harvesting activity? Although there are a lot of netting methods that applicable in horseshoe crab harvesting activity from the wild, all interviewed fishermen in Pahang and Malacca that engaged with the fishing gear in collecting horseshoe crab prefer to apply the drift net.

The obtained data were analyzed in order to calculate the total quantity of horseshoe crab that been harvested per month by 50 respondents at Pahang and Malacca. Data were analyzed to compare the exploitation activity in both coastal areas. Two independent data mean comparisons were performed using Mann-Whiney $U$ test. The analysis was performed using a SPSS package (SPSS 20.0 for windows, SPSS Inc., Chicago, IL, USA). P values of less than 0.05 were considered statistically significant.

\section{Results and Discussion}

Respondents were mostly fisherman which used both techniques; traditional method (hand harvest at shoreline) [24] and netting method [25][26] to harvest the adult horseshoe crab. All interviewed fishermen that engaged with the modern method in Pahang and Malacca prefer to use drift net to harvest horseshoe crab from the wild. The length of the net could exceed to $450 \mathrm{~m}$ and 8 inch mesh size. Horseshoe crab collectors in Pahang were significantly preferred to apply the traditional collecting method (hand harvest at shoreline) (56.1\%) compared to those in Malacca (34.15\%). $65.85 \%$ collectors in Malacca preferred to use the netting technique (modern method) while, only $43.9 \%$ collectors in Pahang adopted the same method to harvest the adult horseshoe crabs during spawning season (Figure 2).

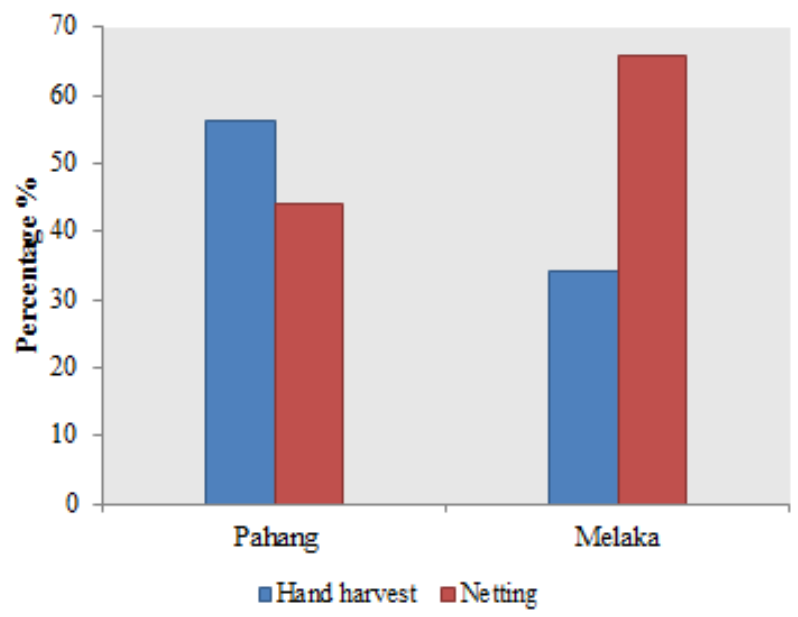

Figure 2. Percentage of the locals that engage with the hand harvest and netting methods in Pahang and Malacca, Malaysia
Interestingly, quantities of the harvested horseshoe crabs per catch within the same method between Pahang and Malacca as shown in Figure 3 were equal ( $p>0.05$ ). Quantity per catch in Malacca by the fishing net was significantly higher than hand harvest $(p<0.05)$ while, there is no significant difference in quantity per catch between netting and hand harvest methods in Pahang ( $>00.05)$. Frequency of netting and hand harvest methods application in Pahang for one person per month were equal $(\mathrm{p}>0.05)$.

The frequency of the fishing net application for one person per month in Malacca was significantly higher $(25 \pm 10$ times $)$ $(p<0.05)$ compared to hand harvest $(2 \pm 1$ times $)$ (Figure 4$)$. The result contradicted with Pahang. Netting method in Malacca returned a higher harvest quantity for 50 respondents (16860 per month) than Pahang (4180 per month).

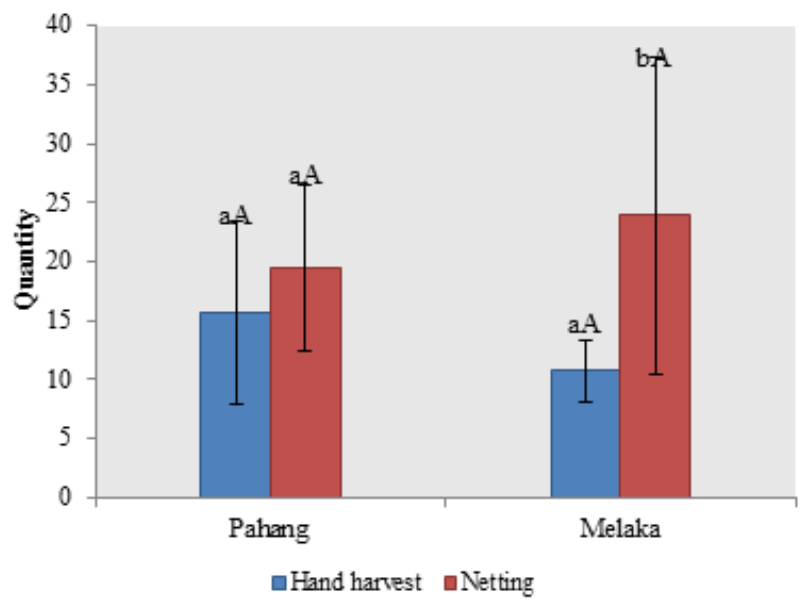

Figure 3. Quantity of the harvested horseshoe crab per catch for one person by the hand harvest at shore and netting methods at open sea in Pahang and Malacca. Different capital letters on the same harvesting method between Pahang and Malacca and different small letters between hand harvest and netting methods in the same study area indicate the significant differences $(\mathrm{p}<0.05)$.

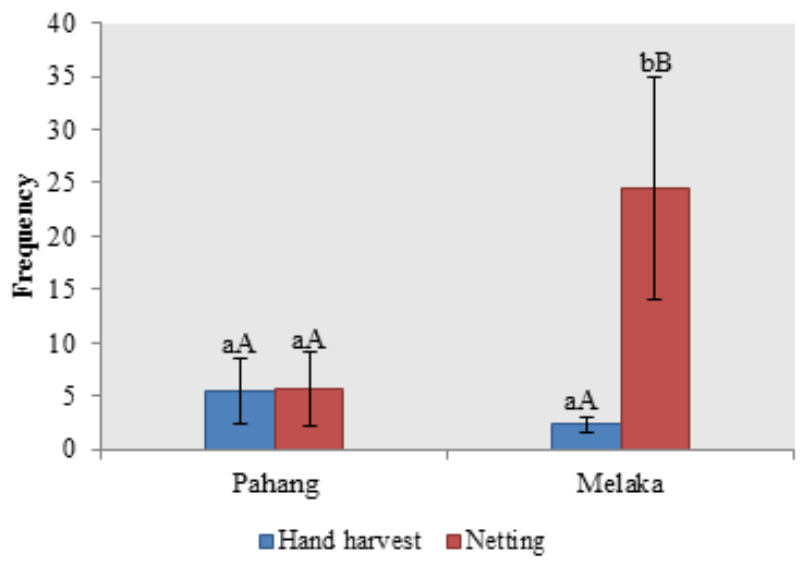

Figure 4. Frequency of the hand harvest and netting method application in Pahang and Malacca for one person per month 
Percentage of the local in Pahang preferred to apply the traditional method in harvesting activity was significantly higher than Malacca. The usage of the traditional method in Pahang might be due to the equal quantities of horseshoe crab that could be harvested per catch by both methods. The lower cost harvesting technique and fishing effort with higher catch quantity may serve as a factor that influenced locals demographic to apply the hand harvest. Moreover, confined horseshoe crabs yield where, no female $T$. gigas entangled in crab nets for past a few years ago at Balok, Pahang [27] might influence the local's interest to use this harvesting method. Balok and Pekan is the main area for spawning population in Pahang which could be due to the suitable beach condition particularly the sand type and grain size [28]. In comparison, lesser number of beaches suitably becomes spawning area for horseshoe crab in Malacca. This is possibly because of intense coastal development and reclamation activities along the Malacca coast. The loss of habitat due to anthropogenic pressure such as pollution and land reclamation remains threats to crab populations and habitat [19] and directly influencing the harvesting status. Land reclamation activity in Malacca by the construction of the wave breaker along the coastal area has decimated the area of the exposed sandy beach that use by horseshoe crabs to spawn.

Higher quantity of the trapped horseshoe crab per catch in fishing net in Malacca compared to hand harvest at shore has influenced the locals to choose netting method. Although the quantity of crabs caught by netting method in Pahang and Malacca were equal, the exploitation frequency per month for netting method in Malacca was significantly higher which could be associated with increase in fishing effort [29]. Lower quantity of the harvested crabs by hand harvest method in Malacca could also be an indicator of the overexploitation by the netting method at the open sea that restrained the opportunity of the crabs to reach the beach area for spawning. Life history strategy of Tachypleus sp. which tends to migrate to sea rather than stay within the beach habitat would also affect the harvest [30].

\section{Conclusions}

This study concludes that the exploitation of horseshoe crab in Pahang was significantly lower compared to Malacca. However, the rapid increases in horseshoe crabs' market value could change the exploitation status in Pahang in future. The initial results from this survey indicate an alarming condition faced by the horseshoe crab coming to the beach for nesting. Monitoring program should be planned for a sustainable fishery activity on horseshoe crab in Malaysia water.

It is highly recommended that studies on $T$. gigas exploitation along the west and east Malaysian coastal areas to be intensified. Since the distribution of the T. gigas could be found along Malaysian coastal areas, the exploitation status of $T$. gigas by the local might be different. Monitoring program should be planned for a sustainable fishery activity on horseshoe crab in Malaysia water.

\section{Acknowledgements}

This study was funded by The Ministry of Higher Education Malaysia under the Fundamental Research Grant Scheme (FRGS 2015-2017), FRGS15-199-0440.

\section{REFERENCES}

[1] Rudkin, D. M., \& Young. G. A. (2009). Horseshoe Crabs - An Ancient Ancestry Revealed. In J. T. Tanacredi, M. L. Botton \& D. R. Smith (Eds.), Biology and Conservation of Horseshoe Crabs. New York, London: Springer Cham Heidelberg.

[2] Behera, S., Tripathy, B., Sivakumar, K., Choudhury, B. C., \& Bhadury, P. (2015). Distribution and Abundance of Two Sympatric Species of Horseshoe Crabs along the Odisha Coast, India. In R. H. Carmichael, M. L. Botton, P. K. S. Shin \& S. G. Cheung (Eds.), Changing Global Perspectives on Horseshoe Crab Biology, Conservation and Management. New York, London: Springer Cham Heidelberg.

[3] Tan, S. G., Adibah, A. B., \& Liew. P. L. (2009). Isolation of Microsatellites Using 5' Anchored PCR for the Horseshoe Crab Tachypleus gigas and Carcinoscorpius rotundicauda in Malaysia. In Zilfalil Alwi, S. G. Tan \& Vijay Kumar (Eds.), Genetik. Selangor, Malaysia: Bulletin PGM.

[4] Lee, C. N., \& Morton, B. (2005). Experimentally Derived Estimates of Growth by Juvenile Tachypleus tridentatus and Carcinoscorpius rotundicauda (Xiphosura) from Nursery Beaches in Hong Kong. Journal of Experimental Marine Biology and Ecology, 318, 39 - 49.

[5] Christianus, A., \& Saad, C. R. (2007). Horseshoe Crabs in Malaysia and the World. Fish Mail, 16, 8 - 9.

[6] IUCN (International Union for Conservation of Nature). (2010). Red List of Threatened Species. [Online]. From: http://www.iucnredlist.org [Accessed on 24 February 2010].

[7] Shakiba Zadeh, Sh., Christianus, A., Saad, C. R., Hajeb, P., \& Kamarudin, M. S. (2009). Comparisons in Prosomal Width and Body Weight among Early Instar Stages of Malaysian Horseshoe Crabs, Carcinoscorpius rotundicauda and Tachypleus gigas in the Laboratory. In J. T. Tanacredi, M. L. Botton \& D. R. Smith (Eds.), Biology and Conservation of Horseshoe Crabs. New York, London: Springer Cham Heidelberg.

[8] Chatterji, A., \& Abidi, S. A. H. J. (1993). The Indian Horseshoe Crab: A Living Fossil. Journal Indian Ocean Studies, 1, $43-48$.

[9] Davidson, G. W. H., Ng, P. K. L., \& Ho, H. C. (2008). The Singapore Red Data Book: Threatened Plants and Animals of Singapore. The Nature Society (Singapore), Singapore.

[10] Shin, P., Li, H. Y., \& Cheung, S. G. (2009). Horseshoe crabs in Hong Kong: Current Population Status and Human 
Exploitation. In J. T. Tanacredi, M. L. Botton, D. R. Smith \& S. A. Earle (Eds.), Biology and Conservation of Horseshoe Crabs. New York, London: Springer Cham Heidelberg.

[11] Kreamer, G., \& Michels, S. (2009). History of Horseshoe Crab Harvest on Delaware Bay. In J. T. Tanacredi, M. L. Botton \& D. R. Smith (Eds.), Biology and Conservation of Horseshoe Crabs. New York, London: Springer Cham Heidelberg.

[12] Kassim, Z., Shahuddin, H., Shaharom, F., \& Chatterji, A. (2008). Abundance of Three Species of the Horseshoe Crab along the Coast of Malaysia. Journal of the Bombay Natural History Society, 105, $209-211$.

[13] John, B. A., Jalal, K. C. A., Kamaruzzaman, B. Y., \& Zaleha, K. (2010). Mechanism in the Clot Formation of Horseshoe Crab Blood during Bacterial Endotoxin Invasion. Journal of Applied Sciences, 10(17), 1930 - 1936.

[14] Naqvi, S. B., Mirza, T., Sheikh, D., \& Abbas, T. (2004). Application of Limulus Amebocyte Lysate (LAL) Test for Detecting Endotoxin (Pyrogen) in Large Volume Parenterals. Journal of Pharmaceutical Sciences, 17(1), 89 - 94.

[15] Gerhart, S. D. (2007). A Review of the Biology and Management of Horseshoe Crabs, With Emphasis on Florida Populations. Fish and Wildlife Research Institute.

[16] Patti, B. (2008). Horseshoe Crabs Galloping Towards Extinction. [Online]. From: http://www.marinenews.com [Accessed on 29 June 2008].

[17] Davis, M. L., Berkson, J., \& Kelly, M. (2006). A Production Modelling Approach to the Assessment of the Horseshoe Crab (Limulus polyphemus) Population in Delaware Bay. Fish Bulletin, 104, 215 - 225.

[18] Robert, R., Muhammad Ali, S., \& Amelia-Ng, P. F. (2015). Demographics of Horseshoe Crab Populations in Kota Kinabalu, Sabah, Malaysia with Emphasis on Carcinoscorpius rotundicauda and Some Aspects of its Mating Behaviour. Journal Tropical Agricultural Science. 37(3), 375 - 388.

[19] Cartwright-Taylor, L., Yap, V. B., Hsu, C. C., \& Tee, L. S. (2011). Distribution and Abundance of Horseshoe Crabs Tachypleus gigas and Carcinoscorpius rotundicauda around the Main Island of Singapore. Aquatic Biology, 13(2), 127 36.

[20] Carmichael, R. H., Rutecki, D., Annett, B., Gaines, E., \& Valiela, I. (2004). Position of Horseshoe Crabs in Estuarine Food Webs: N and C Stable Isotopic Study of Foraging Ranges and Diet Composition. Journal of Experimental Marine Biology and Ecology, 299, 231- 253.
[21] Adibah, A. B., Ng, W. L., \& Tan, S. G. (2009). The Malay Peninsula as a Barrier to Gene Flow in an Asian Horseshoe Crab Species, Carcinoscorpius rotundicauda latreille. Biochemical Systematics and Ecology, 60, $204-210$.

[22] Christianus, A., Harmin, S. A., \& Hussin. L. (2008). Horseshoe Crab: A Fossil Invertebrate Cultured for the Future. Synthesis, 22, 7 .

[23] Botton, M. L., Carmichael, R. H., Shin, P. K. S., \& Cheung, S. G. (2015). Emerging Issues in Horseshoe Crab Conservation: A Perspective from the IUCN Species Specialist Group. In R. H. Carmichael, M. L. Botton, P. K. S. Shin \& S. G. Cheung (Eds.), Changing Global Perspectives on Horseshoe Crab Biology, Conservation and Management. New York, London: Springer Cham Heidelberg.

[24] Tan, A. N., Christianus, A., Shakiba zadeh, S., \& Hajeb, P. (2012). Horseshoe crab, Tachypleus gigas (Müller, 1785) Spawning Population at Balok Beach, Kuantan, Pahang, Malaysia. Pakistan Journal of Biological Sciences, 15, 610 620.

[25] Zaleha K., John, A., Hadnan, N. E. A., Yunus, K., \& Khan Chowdhury, A. J. (2012). Spawning and Nesting Behaviour of Tachypleus gigas along the East Coast of Peninsular Malaysia. International Journal of Biology, 4, $102-111$.

[26] Nelson, B. R. (2015). Nesting Biology of the Horseshoe Crab, Tachypleus gigas (Müller, 1785) in Relation to Changing Environmental Settings at Pantai Balok and Tanjung Selangor, Pahang: PhD dissertation, Universiti Malaysia Terengganu, Malaysia.

[27] Nelson, B. R., Satyanarayana, B., Moh, J. H. Z., Shaharom, F., Sukumaran, M., \& Chatterji, A. (2015). Episodic Human Activities and Seasonal Impacts on the Tachypleus gigas (Müller, 1795) Population at Tanjung Selangor in Peninsular Malaysia. Estuarine, Coastal and Shelf Science, 164, 313 323.

[28] Chiu, H. M. C., \& Morton, B. (2003). The Sediments and Hydrographic Characteristics of Three Horseshoe Crab Nursery Beaches in Hong Kong. Journal of Ocean University of Qingdao, 2, 35 - 43.

[29] Pascoe, S., \& Coglan, L. (2002). The Contribution of Unmeasurable Inputs to Fisheries Production: An Analysis of Technical Efficiency of Fishing Vessels in the English Channel. American Journal Agricultural Economics, 84, 585 597.

[30] Chen, C. P., Yang, M. C., Fan, L. F., Qiu, G., Liao, Y. Y., \& Hsieh, H. L. (2015) Co-Occurrence of Juvenile Horseshoe Crabs Tachypleus Tridentatus and Carcinoscorpius Rotundicauda in an Estuarine Bay, Southwestern China. Aquatic Biology, 24, 117 - 126. 